R.P. Bondar

\title{
RESEARCH OF THE MAGNETOELECTRIC LINEAR OSCILLATORY MOTOR CHARACTERISTICS DURING OPERATION ON ELASTOVISCOUS LOADING
}

\begin{abstract}
Purpose. To development of mathematical model for calculation of the magnetoelectric linear vibration motor performance with elastoviscous loading and research of machine characteristics in the different operational modes depending on loading parameters. Methodology. Experimental results by means of the developed test setup according to the specified methods are obtained. Moreover we have correlated the experimental data obtained by means of the development experimental setup with the simulated results using analytical model of the linear oscillatory motor with elastoviscous loading. In the analytical model of the linear vibration motor a one-mass vibration system with equivalent parameters of stiffness and viscous friction is considered. Results. Calculations of performance data for three operating modes of the oscillatory motor - for constant value of current, constant amplitude and acceleration of vibrations are carried out. Results of calculation by means of analytical model are coordinated with the experimental data obtained with help of a prototype of the linear motor and the load machine. Originality. Analytical expressions for performance data of the linear vibration motor which are based on the analytical model and an equivalent circuit with the lumped parameters are obtained. It is shown that for calculation of performance data depending on parameters of loading it is possible to use analytical model which is based on an equivalent circuit with constant inertial parameters of the linear motor. Practical value. Results of the work can be used for designing new and improvements of the existing vibration devices on the basis of linear motors with the specified performance data. References 7 , tables 1 , figures 7 .
\end{abstract}

Key words: magnetoelectric linear motor, elastoviscous loading, performance data.

Розглянуто магнітоелектричний лінійний двигун вібраційної дії циліндричної топологї̈. Шляхом лінеаризації рівнянь динаміки, отримано вирази для розрахунку робочих характеристик двигуна в залежності від параметрів пружно-в'язкого навантаження. Характеристики визначаються для трьох режимів роботи - для сталого значення струму двигуна та для сталих амплітуди коливань і прискорення. Проведено дослідження в лінійній постановці, де розглядається одномасова коливальна система, в якій параметри навантаження враховуються як еквівалентні коефіцієнти жсорсткості та в'язкого тертя. Для побудови розрахункової схеми заміщення використовується метод електромеханічних аналогій. Проведено експериментальні дослідження робочих характеристик магнітоелектричного двигуна вібраційної дї̈ та виконано порівняльний розрахунок характеристик за допомогою представленої лінійної моделі. Бібл. 7, табл. 1, рис. 7.

Ключові слова: магнітоелектричний лінійний двигун, пружно-в'язке навантаження, робочі характеристики.

Рассмотрен магнитоэлектрический двигатель вибрационного действия цилиндрической топологии. Путем линеаризации уравнений динамики, получены выражсеня для расчета рабочих характеристик двигателя в зависимости от параметров упруго-вязкой нагрузки. Характеристики определяются для трёх режимов работы - для постоянного значения тока двигателя и для постоянных амплитуды колебаний и ускорения. Выполнено исследование в линейной постановке, где рассматривается одномассовая колебательная система, в которой параметры нагрузки учитываются как эквивалентные коэффициенты жесткости и вязкого трения. Для построения расчетной схемы замещения используется метод электромеханических аналогий. Выполнены экспериментальные исследования рабочих характеристик магнитоэлектрического двигателя вибрационного действия, а также сравнительный расчет характеристик с помощью представленной линейной модели. Библ. 7, табл. 1, рис. 7.

Ключевые слова: магнитоэлектрический линейный двигатель, упруго-вязкая нагрузка, рабочие характеристики.

Introduction. Vibration technology is the basis of many modern technological processes associated with the movement and processing of materials, sealing, sorting, granulation, etc. Typically, rotary motors with appropriate mechanical transmissions are used to implement reciprocating propulsion motion. Low efficiency of rotary actuators is caused by significant mechanical losses in transmission devices, and insufficient reliability by dynamic overloads and non-durability of the typical series of induction motors used in them.

Linear motors (LMs) are an alternative to traditional drives based on rotational motors with transmissions that convert the rotational motion into straightforward one. Their advantages include the lack of mechanical gears, low noise, high reliability and improved handling.

The use of vibration devices with a drive from linear motors has its own peculiarities, which are determined by the nature of the operation process. In order for the vibrator to perform a certain technological operation (sealing, mixing, etc.), it is necessary to ensure the conformity of the electromechanical characteristics of the LM to the requirements of the operation process.
A series of works is devoted to the research and calculation of the characteristics of the LM of vibrational action. Considerable attention during the study of such systems was given to the analysis of the dynamic behavior of the drive, depending on the parameters of the LM and the operating frequency [1-3], that is, the frequency characteristics. In this case, the electromechanical system is considered as single-mass, on the basis of a linear substitution circuit with constant lumped parameters. The influence of the parameters of the elastoviscous loading on the frequency characteristics of the LM (in particular the power factor) was investigated in [4]. In [5], limitations were found for using a linear model by comparison with the results of calculations with the help of a refined nonlinear model based on the finite element method. The use of frequency dependent parameters of the substitution circuit [6] allowed expanding the frequency range of the linear model to determine the characteristics of the LM of vibration action.

The above work solves the problem of calculating the characteristics of a vibrator with a drive from LM 
depending on the frequency. In this case, LM parameters are defined, for example, on the basis of finite element analysis. However, the parameters and the nature of the loading, especially when it is variable, have a significant effect on the characteristics. Such a change may result in the emergence of emergency modes, or the inefficient use of the machine and low efficiency. Therefore, the question of researching the performance characteristics of the LM of vibration action depending on the load parameters and the creation of mathematical models for calculating the parameters of the LM with the given performance characteristics is relevant.

The goal of the work is development of a mathematical model for calculating the performance characteristics of the LM of vibration action with elastoviscous loading and the study of the influence of load parameters on the characteristics of the machine in different operating modes.

The results of the work can be used to design new and improve the existing vibration devices on the basis of LM with the given performance.

Influence of load parameters on the characteristics of $L M$ of vibration action. Linear problem definition. To determine the influence of the load parameters on the performance characteristics, we conduct a study using the linear model of the LM of vibration action, characterized by the following assumptions.

The voltage of the power supply and the current of the LM are sinusoidal. The parameters of the machine are constant and do not depend on the mode of operation. An equivalent mechanical circuit (Fig. 1,a) is represented by a concentrated mass $m_{a}$, which performs harmonic vibrations relative to the position of the mechanical equilibrium with the coordinate $x_{a}=0$ under the action of the sinusoidal electromagnetic force of the $\mathrm{LM} F_{e v}\left(i_{v}\right)$. The restorative and dissipative forces are represented by the corresponding coefficients of rigidity of elastic suspension $k_{v}$ and viscous friction $b_{v}$.
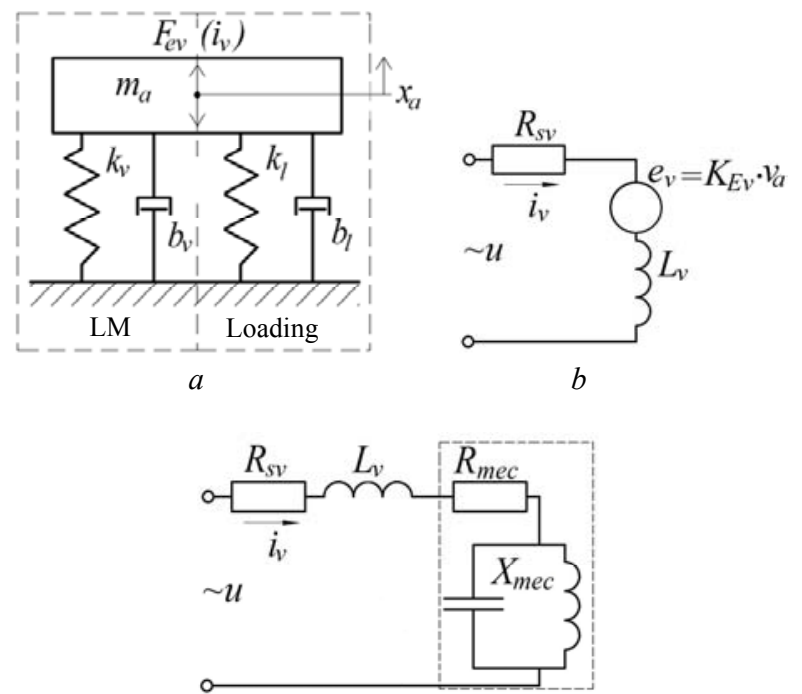

Fig. 1. Equivalent mechanical $(a)$ and electrical circuits $(b, c)$

The force rating of the load is represented by the sum of the elastic component, proportional to the movement of the armature of the $\operatorname{LM} x_{a}$, and the viscous friction force proportional to the velocity $v_{a}$, i.e.

$$
F_{l}\left(x_{a}, v_{a}\right)=k_{l} x_{a}+b_{l} v_{a},
$$

where $k_{l}, b_{l}$ are the respectively, coefficients of rigidity and viscous friction of the loading. A similar nature of the loading is typical, in particular, for compressors drives [4].

It is also considered that the electric circuit of the substitution of the LM (Fig. 1,b) is represented by a series of connected resistance $R_{s v}$, inductance $L_{v}$ (constant averaged value) and source $e_{v}$, which respectively simulate the active resistance of the stator winding, the inductance of the stator winding and the EMF induced by the movement of the armature. The nonlinear properties of the magnetic cores of the machine are neglected.

The following system of differential equations corresponds to the presented substitution circuits:

$$
\left.\begin{array}{l}
u_{v}=i_{v} R_{s v}+L_{v} \frac{d i_{v}}{d t}+K_{E v} v_{a} ; \\
m_{a} \frac{d^{2} x_{a}}{d t^{2}}=F_{e v}\left(i_{v}\right)-F_{l}\left(x_{a}, v_{a}\right)-k_{v} x_{a}-b_{v} \frac{d x_{a}}{d t} \\
\frac{d x_{a}}{d t}=v_{a},
\end{array}\right\}
$$

where $u_{v}=U_{m} \sin (2 \pi f t)$ is the supply voltage of the LM winding; $U_{m}$ is the supply voltage amplitude; $i_{v}$ is the LM stator current; $K_{E v}$ is the coefficient of the EMF of the $\mathrm{LM} ; F_{e v}\left(i_{v}\right)=K_{F v} i_{v}$ is the LM electromagnetic force; $K_{F v}$ is the coefficient of the electromagnetic force.

In the frequency domain, the system (2) is written as $\underline{U}_{v}=\underline{I}_{v}\left(R_{s v}+j \omega L_{v}\right)+K_{E v} \underline{V}_{a}$;

$\left.-m_{a} \omega^{2} \underline{X}_{a}=K_{F v} \underline{I}_{v}-\left(k_{l}+k_{v}\right) \underline{X}_{a}-j \omega\left(b_{l}+b_{v}\right) \underline{X}_{a} ;\right\}$ $j \omega \underline{X}_{a}=\underline{V}_{a}$,

where $\omega$ is the angular frequency of supply voltage and mechanical vibrations.

From the second equation of system (3) we define the displacement

$$
\underline{X}_{a}=\frac{K_{F v} \underline{I}_{v}}{k_{l}+k_{v}-m_{a} \omega^{2}+j \omega\left(b_{l}+b_{v}\right)} .
$$

Having selected the real and imaginary parts of equation (4) and taking the initial phase of current of the LM equal to zero, it is possible to determine the amplitude of vibrations through the corresponding components of the complex displacement

$$
X_{a m}=\frac{K_{F v} I_{v m}}{\sqrt{\left(k_{l}+k_{v}-m_{a} \omega^{2}\right)^{2}+\omega^{2}\left(b_{l}+b_{v}\right)^{2}}},
$$

where $I_{v m}$ is the amplitude value of the LM winding current.

To determine the resonant frequency, we find the derivative of (5) by frequency and equate it to zero, from where

$$
\omega_{r}=\sqrt{\frac{k_{l}+k_{v}}{m_{a}}-\frac{\left(b_{l}+b_{v}\right)^{2}}{2 m_{a}^{2}}} .
$$

Consider how the properties of a vibration system change depending on the load parameters.

From equation (5) it follows that when $k_{l}+k_{v}<m_{a} \omega^{2}$, the growth of the coefficient $k_{l}$ leads to an 
increase in the amplitude of vibrations, and if $k_{l}+k_{v}>m_{a} \omega^{2}$ to decrease. An increase in the damping factor $b_{l}$ leads to a decrease in the amplitude of vibrations and vice versa.

We consider other characteristics of the LM of vibration action, using the method of electromechanical analogies. For this it is convenient to introduce a mechanical link of the system with appropriate supports, the values of which can be obtained from the following.

From equation (4) it follows that

$$
j \omega \underline{X}_{a}=\underline{V}_{a}=\frac{j \omega K_{F v} \underline{I}_{v}}{k_{l}+k_{v}-m_{a} \omega^{2}+j \omega\left(b_{l}+b_{v}\right)} .
$$

Substituting this expression in the first equation of system (3), we obtain

$$
\underline{U}_{v}=\underline{I}_{v}\left(R_{s v}+j \omega L_{v}+\frac{j \omega K_{F v} K_{E v}}{k_{l}+k_{v}-m_{a} \omega^{2}+j \omega\left(b_{l}+b_{v}\right)}\right),
$$

where it can be seen that the complete resistance of the system has electrical $\underline{Z}_{e}=R_{s v}+j \omega L_{v}$ and mechanical

$$
\underline{Z}_{m e c}=\frac{j \omega K_{F v} K_{E v}}{k_{l}+k_{v}-m_{a} \omega^{2}+j \omega\left(b_{l}+b_{v}\right)} \text { components. }
$$

By analogy with electric circuits, active and reactive mechanical resistances are defined respectively as real and imaginary parts of the complex full mechanical resistance, that is,

$$
\begin{gathered}
\underline{Z}_{m e c}=\frac{K_{F v} K_{E v}\left(b_{l}+b_{v}\right) \omega^{2}}{\left(k_{l}+k_{v}-m_{a} \omega^{2}\right)^{2}+\left(b_{l}+b_{v}\right)^{2} \omega^{2}}+ \\
+j \frac{\omega K_{F v} K_{E v}\left(k_{l}+k_{v}-m_{a} \omega^{2}\right)}{\left(k_{l}+k_{v}-m_{a} \omega^{2}\right)^{2}+\left(b_{l}+b_{v}\right)^{2} \omega^{2}} .
\end{gathered}
$$

The real part of expression (7) is the active mechanical resistance

$$
R_{m e c}=\frac{K_{F v} K_{E v}\left(b_{l}+b_{v}\right) \omega^{2}}{\left(k_{l}+k_{v}-m_{a} \omega^{2}\right)^{2}+\left(b_{l}+b_{v}\right)^{2} \omega^{2}},
$$

and the imaginary one is the reactive mechanical resistance

$$
X_{m e c}=\frac{\omega K_{F v} K_{E v}\left(k_{l}+k_{v}-m_{a} \omega^{2}\right)}{\left(k_{l}+k_{v}-m_{a} \omega^{2}\right)^{2}+\left(b_{l}+b_{v}\right)^{2} \omega^{2}} .
$$

The appropriate substitution circuit is presented in Fig. 1,c.

After determining the resistance, the LM power factor can be determined according to the expression

$$
P F_{v}=\frac{R_{s v}+R_{m e c}}{\sqrt{\left(R_{s v}+R_{m e c}\right)^{2}+\left(X_{s v}+X_{m e c}\right)^{2}}},
$$

where $X_{s v}=\omega L_{v}$ is the reactance of the LM winding.

According to the substitution circuit shown in Fig. 1,c, the current value of the supply voltage of the LM is determined from the expression

$$
U_{v}=I_{v} \sqrt{\left(R_{s v}+R_{m e c}\right)^{2}+\left(X_{s v}+X_{m e c}\right)^{2}} .
$$

Then the power consumption will be equal

$$
P_{v}=U_{v} I_{v} P F_{v} .
$$

One of the possible operating modes of the LM of vibration action is the mode when the constant value of current $I_{v}=$ const is supported in the winding. The amplitude of vibrations, the power factor, the voltage and the power of the LM, for this mode, can be determined by the expressions $(5,8-10)$ respectively. Such a mode of operation is favorable in order to avoid electrical overloads, but it does not exclude mechanical overloads. In addition, this mode is not always optimal for providing the necessary mechanical characteristics of the drive (amplitude, speed, driving force or acceleration of the working body). Therefore, it is also advisable to consider the problem when it is necessary to determine the current of the LM, the properties of the elastic system and the coefficient of electromagnetic force for the given mechanical characteristics. As the latter, we consider the modes when the steady amplitude of vibrations $X_{a m}=$ const and the steady acceleration $A_{a m}=$ const should be ensured.

From expression (5), the current value of the current, which provides the required amplitude of vibrations, will be equal to

$$
\left.I_{v}\right|_{X_{a m}=\mathrm{const}}=\frac{X_{a m} \sqrt{\left(k_{l}+k_{v}-m_{a} \omega^{2}\right)^{2}+\omega^{2}\left(b_{l}+b_{v}\right)^{2}}}{\sqrt{2} K_{F v}}
$$

where it is seen that when $k_{l}+k_{v}<m_{a} \omega^{2}$, the growth of the coefficient $k_{l}$ leads to a decrease in the current required to maintain a constant amplitude of vibrations, and if $k_{l}+k_{v}>m_{a} \omega^{2}$ to increase. The increase in the damping factor $b_{l}$ leads to an increase in the current of the LM and vice versa.

The steady acceleration mode $A_{a m}=X_{a m} \omega^{2}=$ const, provided that the vibration mass is constant, also ensures the constancy of the inertia force, since the latter equals $F_{0}=m_{a} X_{a m} \omega^{2}$.

Taking into account the above, the current value of the LM current, for a constant acceleration mode, is determined from the expression

$$
A_{a m}=\frac{K_{F v} I_{v m} \omega^{2}}{\sqrt{\left(k_{l}+k_{v}-m_{a} \omega^{2}\right)^{2}+\omega^{2}\left(b_{l}+b_{v}\right)^{2}}},
$$

where

$$
\left.I_{v}\right|_{A_{a m}=\mathrm{const}}=\frac{A_{a m} \sqrt{\left(k_{l}+k_{v}-m_{a} \omega^{2}\right)^{2}+\omega^{2}\left(b_{l}+b_{v}\right)^{2}}}{\sqrt{2} K_{F v} \omega^{2}}
$$

Voltage, power factor and power for the last two modes can be calculated by the expressions (8-10) taking into account $(11,12)$.

The connection of the above characteristics with the main dimensions and parameters of the LM is determined by the coefficient of electromagnetic force [7] $K_{F v}=\Psi_{m} \pi / \tau$, where $\Psi_{m}$ is the amplitude of the flux linkage of the winding; $\tau$ is the pole division.

Design of experimental LM of vibration action and loading machine. Both experimental and loadbearing machines have cylindrical configuration. The stator of the experimental machine (Fig. 2,a) has a laminated core 1 of electrical steel and a winding of two coils 2 . An armature of the machine contains a permanent magnet magnetized in axial direction 3 and two poles 4, which are made of structural steel and have radial incisions for reduction of eddy currents. 

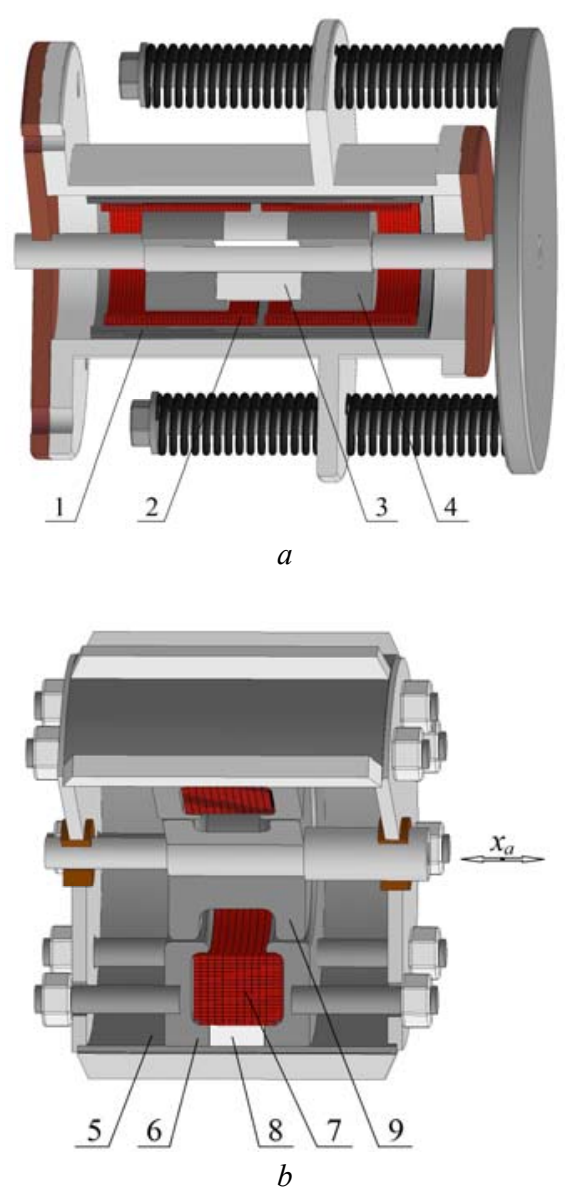

Fig. 2. Design of experimental ( $a$ ) and loading (b) machines

The loading of the experimental motor is carried out using the loading machine shown in Fig. 2,b. The stator of the machine contains a body 5, a core with two ferromagnetic poles 6 , between which there is a winding 7. In order to improve the specific power indicators, in a stator core a permanent magnet 8 of toroidal shape with an axial direction of magnetization is used. The electromagnetic force of the machine is determined by the force and direction of the current in the winding, as well as the position of the ferromagnetic armature 9 relative to the stator. Stator poles and armature are solid and have radial incisions to reduce eddy currents.

The main design parameters of experimental and loading machines are given in Table 1.

In accordance with the above mechanical and electrical substitution circuits (see Fig. 1), the parameters for the calculation of performance characteristics are as follows.

The mass of the oscillating part (the total mass of the armatures of the experimental and loading machinery, as well as the attached weight of the elastic suspension) is $m_{a}=6.72 \mathrm{~kg}$. Elastic suspension of the LM has rigidity $k_{v}=153291 \mathrm{~N} / \mathrm{m}$, coefficient of viscous friction $b_{v}=44.9 \mathrm{~kg} / \mathrm{s}$.

Parameters if the electrical substituting circuit of the LM (see Fig. 1,b) are: $K_{F v}=K_{E v}=13.1 ; R_{s v}=3.1 \Omega$; $L_{v},=0.02 \mathrm{H}$.

The parameters of the loading machine vary depending on the supply current and are within range $b_{l}=(17 \div 31) \mathrm{kg} / \mathrm{s}, k_{l}=(3600 \div 26100) \mathrm{N} / \mathrm{m}$.
Table 1

Design parameters of experimental and drive machines

\begin{tabular}{|c|c|c|c|c|}
\hline \multirow{4}{*}{$\begin{array}{l}\text { : } \\
\text { : } \\
\stackrel{\mathbb{Z}}{\Xi}\end{array}$} & \multicolumn{2}{|c|}{ Amplitude of vibrations (operating) } & $\mathrm{mm}$ & 10 \\
\hline & \multicolumn{4}{|c|}{ Armature } \\
\hline & \multirow{2}{*}{$\begin{array}{l}\text { Permanent } \\
\text { magnet }\end{array}$} & \multirow{2}{*}{$\begin{array}{l}\text { material } \\
\text { residual magnetic } \\
\text { flux density }\end{array}$} & \multicolumn{2}{|c|}{$\mathrm{NdFeB}(\mathrm{N} 42)$} \\
\hline & & & $\mathrm{T}$ & 1.3 \\
\hline \multirow{6}{*}{$\begin{array}{l}\text { T. } \\
0 \\
0 \\
0\end{array}$} & \multicolumn{4}{|c|}{ Stator } \\
\hline & \multirow{2}{*}{ Magnetic core } & outer diameter & $\mathrm{mm}$ & 89 \\
\hline & & length & $\mathrm{mm}$ & 165 \\
\hline & \multirow{2}{*}{ Stator windings } & wire section & $\mathrm{mm}^{2}$ & 1.06 \\
\hline & & number of turns & - & 300 \\
\hline & \multicolumn{2}{|c|}{ Pole division } & $\mathrm{mm}$ & 79 \\
\hline \multirow{11}{*}{ 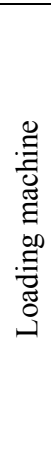 } & Operation vi & ation amplitude & $\mathrm{mm}$ & 10 \\
\hline & \multicolumn{4}{|c|}{ Physical parameters } \\
\hline & \multirow[b]{2}{*}{$\begin{array}{l}\text { Permanent } \\
\text { magnet }\end{array}$} & material & \multicolumn{2}{|c|}{$\mathrm{NdFeB(N42)}$} \\
\hline & & $\begin{array}{l}\text { residual magnetic } \\
\text { flux density }\end{array}$ & $\mathrm{T}$ & 1.3 \\
\hline & Armature & material & \multicolumn{2}{|c|}{ Steel 3} \\
\hline & \multirow{2}{*}{ Winding } & number of turns & \multicolumn{2}{|c|}{380} \\
\hline & & wire & \multicolumn{2}{|c|}{ ПСД, Ø1.12 } \\
\hline & \multicolumn{4}{|c|}{ Main dimensions } \\
\hline & \multicolumn{2}{|c|}{ Pole division } & $\mathrm{mm}$ & 36 \\
\hline & \multirow{2}{*}{$\begin{array}{l}\text { Overall } \\
\text { dimensions }\end{array}$} & diameter & $\mathrm{mm}$ & 160 \\
\hline & & length & $\mathrm{mm}$ & 120 \\
\hline
\end{tabular}

Experimental study of the performance characteristics of the $\mathrm{LM}$ of vibration action. Investigation of LM characteristics, depending on the load parameters, was carried out on the experimental stand presented in Fig. 3.

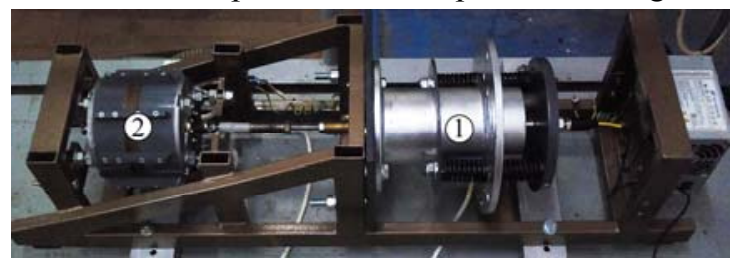

$a$

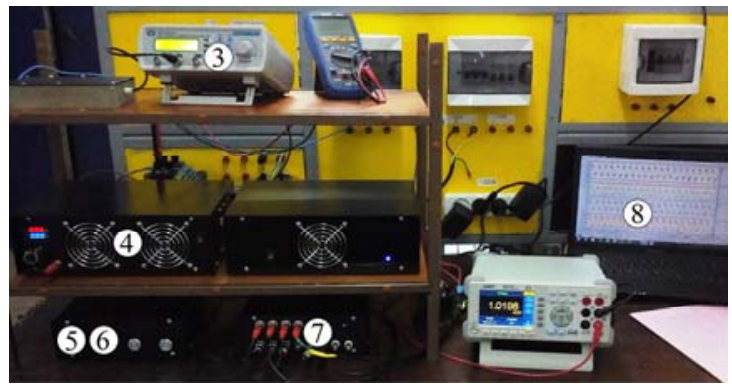

$b$

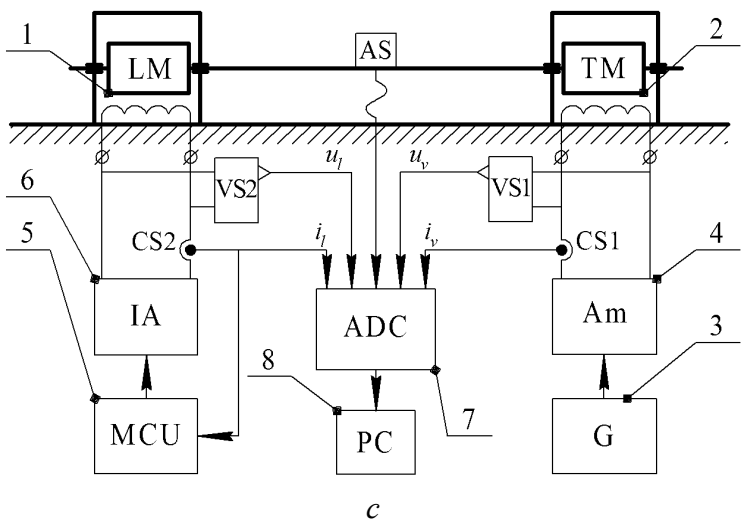

Fig. 3. Stand for the study of the characteristics of the LM of vibration action: $a, b$ - external view; $c$ - circuit 
The armature of the experimental LD of vibration action 1 (LM) is rigidly connected to the armature of the loading machine 2 (TM). The power supply of the experimental machine is carried out from a sinusoidal source, which is realized with the help of generator $3(\mathrm{G})$ and amplifier 4 (Am).

During experiments, a constant current value is maintained in the winding of the loading machine. To do this, a hysteresis current controller, made on microcontroller 5 (MCU), which controls the inverter 6 (IA), is used.

Measurement of voltages, currents of the LM and loading machine is performed using sensors VS1, VS2, $\mathrm{CS} 1$, CS2. The installation is equipped with an accelerometer AS, which is attached to the armature of the experimental machine. Measured values signals are fed to the multichannel measuring unit ADC 7 (ADC) and transmitted to the computer 8 (PC), which acts as a recorder.

Fig. 4 shows the dependencies of controlled quantities as time functions for the case when: $I_{v}=4.75 \mathrm{~A} ; I_{l}=-2 \mathrm{~A} ; X_{a m}=0.0048 \mathrm{~m} ; f=23.5 \mathrm{~Hz}$.

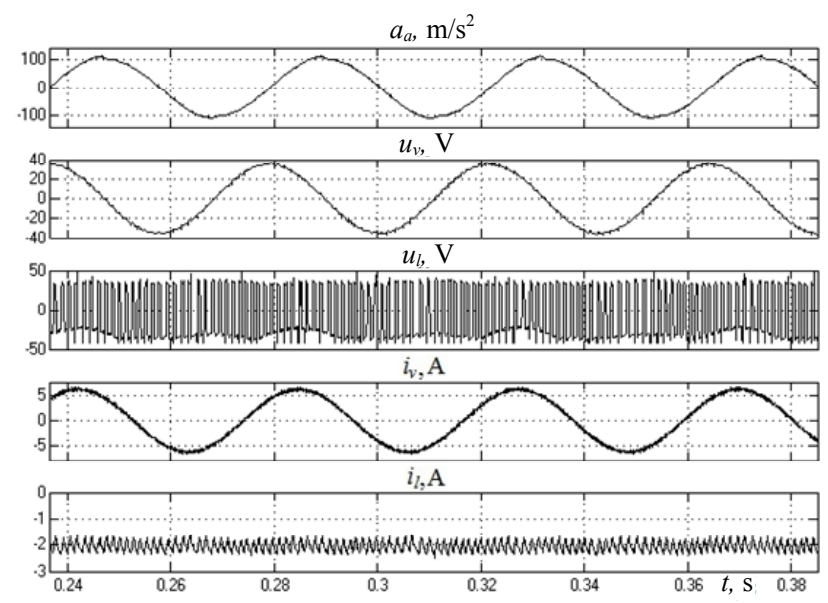

Fig. 4. Voltages and currents of the $\operatorname{LM}\left(u_{v}, i_{v}\right)$ and loading machine $\left(u_{l}, i_{l}\right), a_{a}-$ accelerations

The presented below experimental operational characteristics are obtained as a result of appropriate processing and recalculation of the time charts of the measured values, namely:

- determining effective values of the voltage $U_{v}$ and current $I_{v}$ of the motor

$$
U_{v}=\sqrt{\frac{1}{T} \int_{t-T}^{t} u_{v}^{2} d t} ; I_{v}=\sqrt{\frac{1}{T} \int_{t-T}^{t} i_{v}^{2} d t}
$$

- determined average value of the loading machine current $I_{l}$

$$
I_{l}=\frac{1}{T} \int_{t-T}^{t} i_{l} d t
$$

- determining vibration amplitude

$$
\left|X_{a m}\right|=\frac{\sqrt{a_{n}^{2}+b_{n}^{2}}}{\omega^{2}}
$$

where $a_{n}=\frac{2}{T} \int_{t-T}^{t} a_{a} \cos (n \omega t) d t ; \quad b_{n}=\frac{2}{T} \int_{t-T}^{t} a_{a} \sin (n \omega t) d t$ are the coefficients of the Fourier series; $n$ is the order of the harmonic (and $n=1$, that is, the calculation was carried out according to the basic harmonic frequency of the mechanical oscillations $\omega) ; T=1 / f$ is the period;

- calculating active power $P_{v}$ and power factor $P F_{v}$ of the motor

$$
P_{v}=\frac{1}{T} \int_{t-T}^{t} u_{v} i_{v} d t ; \quad P F_{v}=\frac{P_{v}}{U_{v} I_{v}}
$$

In Fig. 5 marker shows the experimental characteristics of the LM of vibration action for the operating mode when it's current is constant $-I_{v}=4.75 \mathrm{~A}$. Characteristics are presented for three values of the frequency: $24.2 ; 24.9 ; 25.6 \mathrm{~Hz}$. In this frequency range, with given LM and load parameters, the system is near the frequency of mechanical resonance $\omega_{r}$.

The lines show the calculation results using the above linear model. The corresponding dependencies were determined by the equations $(5,8-10)$.

Amplitude of vibrations (Fig. 5,a), for the mode $I_{v}=$ const, has clearly expressed maxima corresponding to the parameters of the mechanical resonance at the corresponding frequencies. The maximum value of the amplitude decreases with increasing damping coefficient of loading $b_{l}$, which also follows from equation (5). As a result of the decrease in the amplitude of vibrations (and hence the velocity), the voltage $K_{E v} v_{a}$, which is included in the equation of the balance of the system voltage (2), decreases. Therefore, with the increase of damping, the value of the voltage required to provide a constant current decreases (Fig. 5,b).

Several factors influence on the form of dependencies of the power factor $P F_{v}$ on the load parameters (Fig. 5,c). Depending on the frequency and parameters, the mechanical resistance can be activeinductive or active-capacitive. In the latter case, electrical resonance is possible if the value of the capacitive mechanical resistance is balanced by the inductive resistance of the LM. During the passage through the frequency $\omega=\sqrt{\left(k_{l}+k_{v}\right) / m_{a}}$, reactive mechanical resistance changes its character from inductive to capacitive or vice versa [5]. The change in the power factor from the coefficient of rigidity of the loading $k_{l}$ depends on how the latter differs from the value corresponding to the change in the sign of the reactive resistance, i.e. $k_{l}=\omega^{2} m_{a}-k_{v}$. Changing the mechanical resistances (active and reactive) will determine the nature of the change (increase or decrease) of the power factor.

In Fig. 6 marker shows the experimental characteristics of the LM of vibration action for the mode of the steady-state vibration amplitude $X_{a m}=0.007 \mathrm{~m}$. 

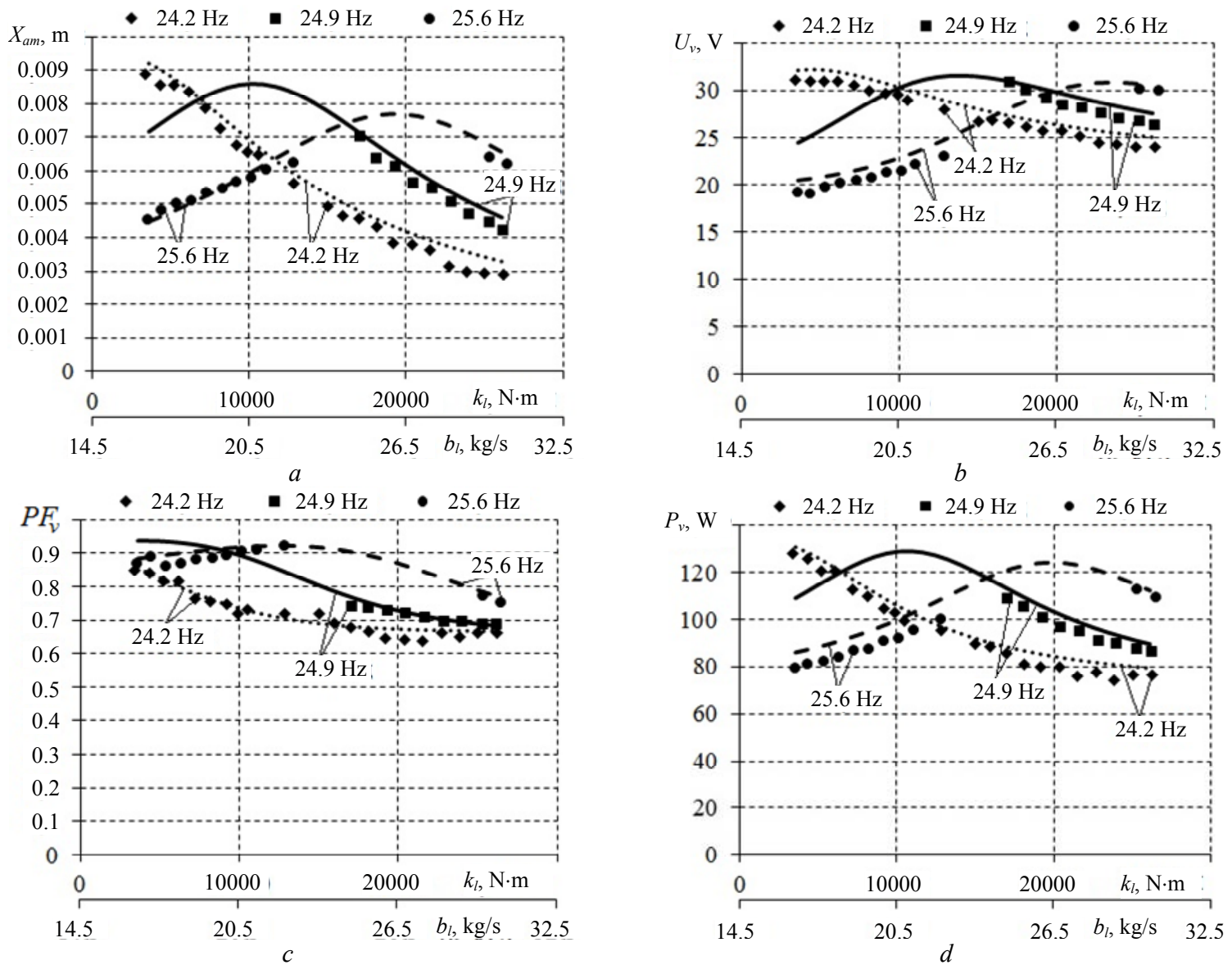

Fig. 5. Characteristics of the LM of vibration action for the mode $I_{v}=$ const
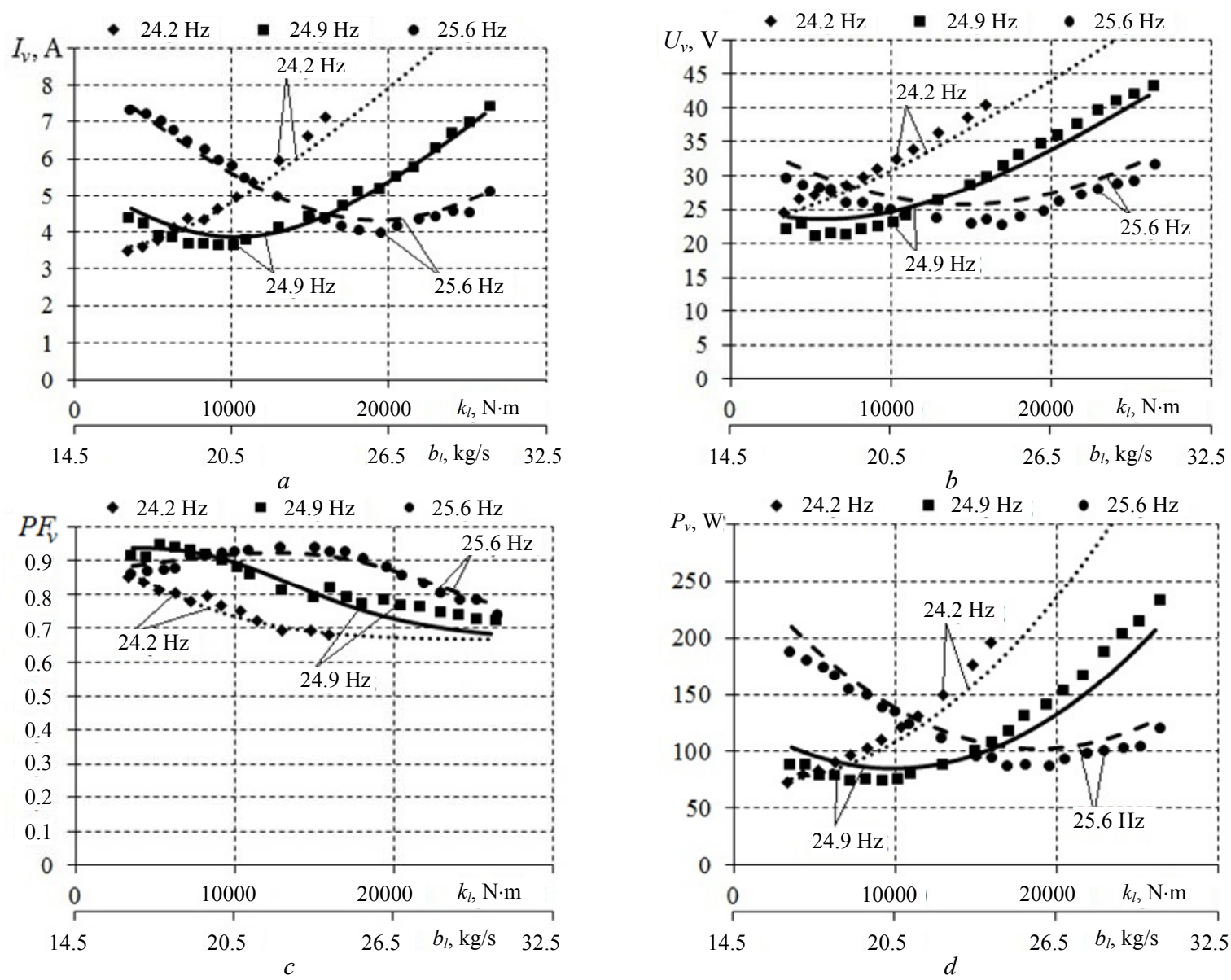

Fig. 6. Characteristics of the LM of vibration action for the mode $X_{a m}=$ const 
The lines show the calculation results using a linear model. The corresponding dependencies were determined according to the equations (8-11).

In this mode there is a significant change in the current and voltage of the LM. The minimum value of current (Fig. 6,a) approximates to the parameters of mechanical resonance, which in particular follows from equation (11). From this equation, it is also seen that with the increase of the coefficient $b_{l}$, increased current values are needed to provide given amplitude of vibrations.

In Fig. 7 marker shows the experimental dependencies of the LM characteristics on load parameters for the case of steady acceleration $A_{a m}=192 \mathrm{~m} / \mathrm{s}^{2}$ (in amplitude).

The lines show the results of the calculation of characteristics using a linear model. The corresponding dependencies were determined by the equations $(8-10,12)$.
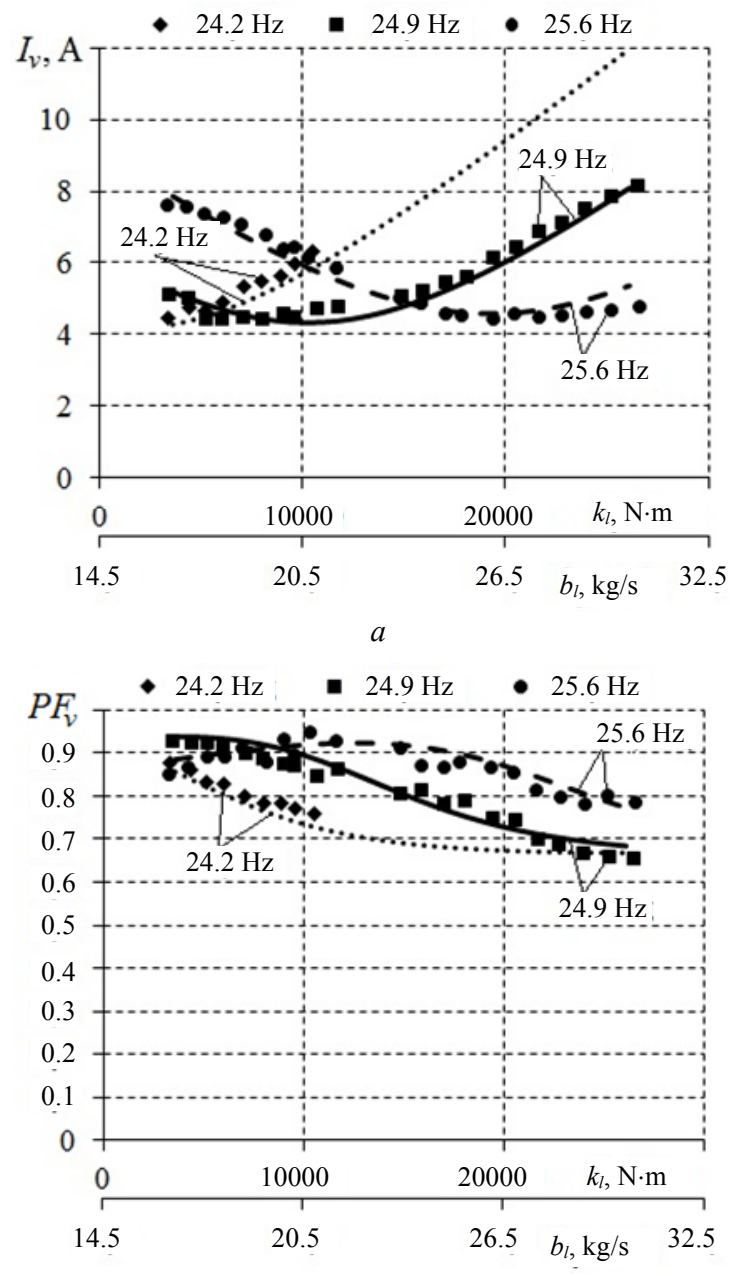

$c$

The characteristics for a stable acceleration case are similar to those for stable amplitude of vibrations, since the quantities are proportional. The difference lies in the fact that in this mode, with increasing frequency, the amplitude of vibrations decreases, and the form of the characteristics varies less depending on the frequency. Therefore, the minimum values of current, voltage and power corresponding to the near-resonance parameters are close and slightly increase with increasing frequency.

As can be seen from Fig. 5-7, the results of calculations according to the linear model are satisfactorily consistent with the experimental data. Since the operating frequency range is relatively small $(\Delta f=1.4 \mathrm{~Hz})$, the machine parameters change practically does not appear depending on the frequency, which makes it possible to use the steady values of LM parameters for the calculation of the operating characteristics.
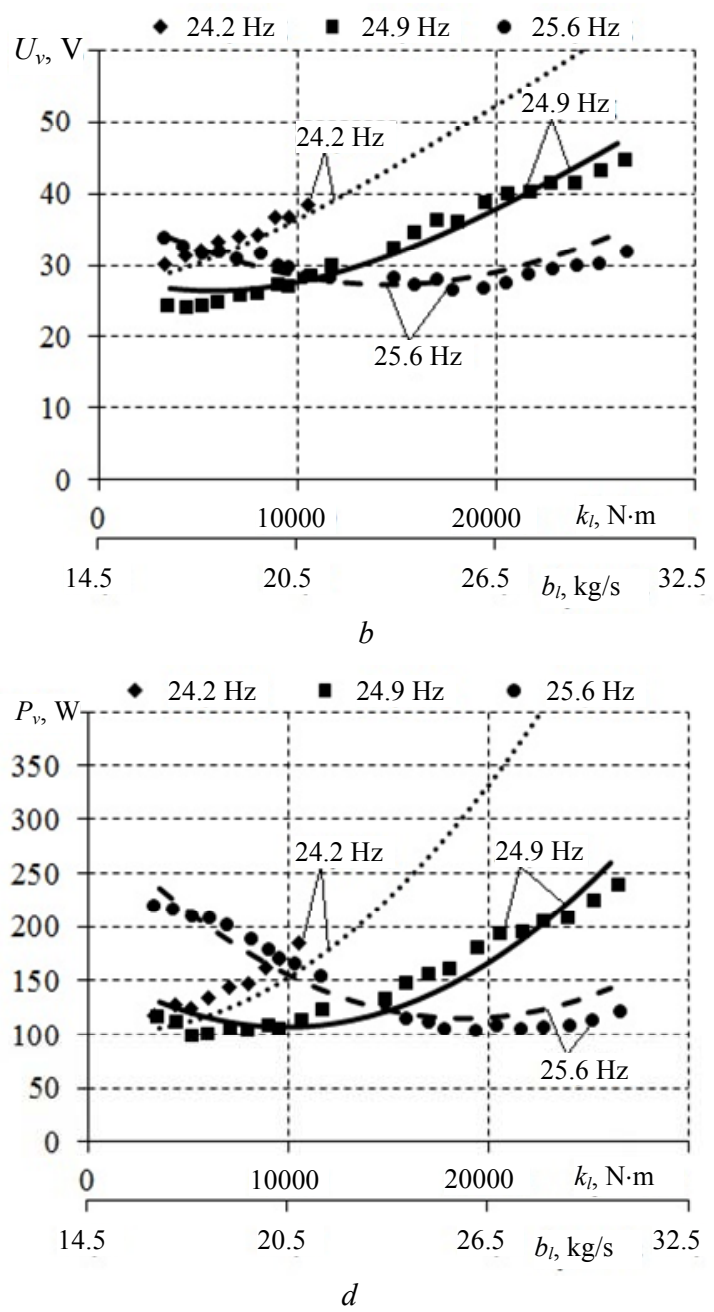

Fig. 7. Characteristics of the LM of vibration action for the mode $A_{a m}=$ const

\section{Conclusions.}

1. In the paper analytical expressions for the performance characteristics of a linear motor of vibration action based on a linear model and a substitution circuit with lumped parameters are obtained.

2. The calculation of performance characteristics for three modes of operation - for the constant value of current, constant amplitude and acceleration of oscillations is carried out. The results of the calculations according to the linear model are satisfactorily consistent with the experimental data obtained using the prototype of the LM and loading linear machine.

3. In the mode of constant current, the operating amplitude of oscillations has clearly expressed maxima that correspond to the parameters of mechanical resonance. The maximum value of the amplitude 
decreases with increasing damping coefficient of the loading.

4. In the mode of steady-state oscillation amplitude there is a significant change in the current and voltage of the LM. The minimum value of the current approximates to the parameters of mechanical resonance. Also, with increasing damping coefficient, increased current value is needed to provide given amplitude of oscillations.

5. The form of the characteristics for the case of steady acceleration changes little depending on frequency. Therefore, the minimum values of current, voltage and power corresponding to the near-resonance parameters are close and slightly increase with increasing frequency.

6. It is shown that in order to calculate the performance characteristics, depending on the load parameters, a linear model based on the substitution circuit with steady, inertial values of LM parameters can be used.

\section{REFERENCES}

1. Jang-Young Choi, Han-Bit Kan. Comparison and dynamic behavior of moving-coil linear oscillatory actuator with/without mechanical spring driven by rectangular voltage source. Journal of International Conference on Electrical Machines and Systems, 2014, vol.3, no.4, pp. 394-397. doi: 10.11142/jicems.2014.3.4.394.

2. Kyu-Hwan Hwang, Yun-Hyun Cho. Design and dynamic characteristics analysis of moving magnet linear actuator for human. Proceedings of the IEEE International Conference on
Mechatronics, 2004, pp. 251-254. doi: 10.1109/ICMECH.2004.1364447.

3. Watada M. Kinetic characteristics of cylindrical moving coil linear DC motor for vibrator. 7th International Conference on Electrical Machines and Drives, 11-13 September 1995, pp. 359-362. doi: 10.1049/cp:19950894.

4. Yu M., Ye Y., Lu Q., Xia Y. A study on power factor of linear oscillatory motor with two separated stators. 2009 International Conference on Electrical Machines and Systems (ICEMS 2009), Nov. 2009, pp. 1-5. doi: 10.1109/icems.2009.5382915.

5. Bondar R.P., Golenkov G.M., Lytvun A. Yu., Podoltsev A.D. Modelling of power characteristics of the vibrator with a linear electric drive. Electromechanical and energy saving systems, 2013, no.2, pp. 66-74. (Ukr).

6. Bondar R.P., Podoltsev A.D. Complex model with frequency dependent parameters for electrodynamic shaker characteristics. Technical electrodynamics, 2017, no.1, pp. 4451. (Ukr). doi: 10.15407/techned2017.01.044.

7. Bondar R.P. Definition of parameters of an equivalent circuit of the linear electrodynamic vibrator. Part 1. Mining, construction, road and melioration machines, 2015, no.85, pp. 109-118. (Ukr).

Received 24.09.2018

R.P. Bondar, Candidate of Technical Science, Associate Professor,

Kyiv National University of Construction and Architecture, 31, Povitroflotsky Ave., Kyiv, 03037, Ukraine, phone +380 44 2415510, e-mail: rpbondar@gmail.com

How to cite this article:

Bondar R.P. Research of the magnetoelectric linear oscillatory motor characteristics during operation on elastoviscous loading. Electrical engineering \& electromechanics, 2019, no.1, pp. 9-16. doi: 10.20998/2074-272X.2019.1.02. 